\title{
LAS INSTITUCIONES CRÍTICAS EN LA ERA DIGITAL
}

\author{
José Luis González Quirós \\ Universidad Rey Juan Carlos. Madrid
}

Resumen: La revolución diǵital no solo está suponiendo transformaciones de enorme importancia en formas de comunicación y de relaciones entre personas, sino que implica la posibilidad de cambios de carácter cultural que están operando fuertemente sobre nuestras actuales sociedades de masas, y es necesario preguntarse de qué modo se han de redefinir, en el caso en que resulte posible, el papel de instituciones culturales clásicas como las editoriales, la prensa o las universidades.

Palabras clave: cultura digital, era digital, realidad, verdad, original, copia, tecnología, fantasía, imaǵinación, deseo, realismo.

Critical institutions in the digital age

Abstract: The digital revolution is not only bringing about enormously important transformations in forms of communication and relationships between people, but it also entails the possibility of cultural changes that are operating strongly on our current mass societies. It is necessary to ask ourselves how the role of classical cultural institutions such as publishing houses, the press or universities should be redefined, if possible.

Keywords: digital culture, digital era, reality, truth, original, copy, technology, fantasy, imaǵination, desire, realism.

Recibido: 16/10/2018. Aprobado: 21/12/2018.

Llamaré instituciones críticas a aquellas que han tomado históricamente a su cargo la creación, la defensa y la promoción de las diversas formas del conocimiento posible y su articulación como soporte de las normas morales y legales, pero también de los valores sociales y políticos que han permitido el desarrollo de la única civilización que ahora mismo se ha adueñado, casi universalmente, del planeta, aunque esta última afirmación merecería un alto número de matices si nos fijamos en algo más que en las prácticas económicas y tecnológicas. De todos modos, para el asunto que aquí vamos a abordar, son esenciales estas dos características, primero el indiscutible reinado de la tecnología y del mercado, segundo la falta de consenso suficiente sobre lo que podríamos llamar una ontología capaz de soportar éticas y políticas cuyos 
fundamentos y prácticas básicas gozasen de un nivel de consenso universal. Como es obvio, la idea de verdad ha sido absolutamente básica para el sostenimiento de buena parte de esas convicciones tan generales, $\mathrm{y}$ el hecho de que se trate de una idea muy sometida a cuestionamiento puede contribuir a que se entiendan buena parte de las tribulaciones que nos afectan.

Estas instituciones han soportado los oficios y las funciones que han sido necesarias para que la vida humana esté apoyada en principios y valores que, generalmente, han gozado de una aceptación muy amplia, porque han sido asumidos en su forma más operativa por la mayoría de las personas, aunque hayan sido analizados, perfilados, cuestionados y puestos al día mediante el trabajo intelectual de los agentes de esas instituciones, sean científicos, ingenieros, sacerdotes, artistas, pensadores, escritores, políticos, banqueros o periodistas. Naturalmente cada uno de esos oficios ha actuado de manera muy distinta, y parte del desconcierto actual (en la medida que admitamos que existe algo como eso) puede explicarse por la frecuente hibridación de formas de actuar de unos y otros, una improvisación que seguramente no ha nacido de la mera inepcia o de cierta maldad, cualidades que tampoco hay que descartar por completo, sino de los profundos cambios que se están experimentando en todas partes.

Siempre hay un riesgo muy alto en la mezcla de cuestiones sociológicas con análisis que bien podríamos considerar, digamos, metafísicos, pero me parece que esa amenaza no es evitable desde el momento en que hemos admitido que la condición de la vida humana es histórica y territorial, en el sentido en el que los biólogos emplean este término, conforme a la envoltura conceptual que de esas dimensiones ha hecho la idea de cultura que ha alcanzado mayor vigencia ${ }^{1}$. Resulta evidente que las ataduras humanas respecto al tiempo, a la historia, y el espacio, a la sociedad en que se vive, configuran en la actualidad una situación enteramente nueva porque el tremendo ímpetu de la globalización, un fenómeno ya viejo de siǵlos pero que ha alcanzado en décadas recientes un ritmo vertiginoso, ha hecho saltar

\footnotetext{
${ }^{1}$ Sobre los suficientemente distintos conceptos de cultura que en ocasiones se mezclan y confunden con cierta ligereza, puede verse González Quirós (2003). 
por los aires la vigencia de la mayor parte de las tradiciones y el vigor de los vínculos sociales mejor establecidos.

De lo que hablaremos aquí es, precisamente, de ciertos rasgos que definen lo que podemos llamar la cultura digital, en especial de aquellos que nos han permitido hablar de una era histórica con ese calificativo, la era digital, y de la forma en que esos caracteres pueden modificar, y de en qué medida lo han hecho ya, una idea previa de la naturaleza humana, de lo que somos, y, muy en especial del papel que en nuestras vidas ocupa la información, entendiendo ahora por tal lo que creemos saber, pero, sobre todo, lo que nos vemos en la necesidad de suponer. Me referiré, por tanto, a las circunstancias que han afectado al conjunto de ideas que se alumbraron en la problemática, pero efectiva, síntesis que se produjo como resultado del debate entre la Ilustración y la tradición anterior, es decir a las ideas clave de la cultura occidental y cristiana, que han incorporado de alguna manera su propia revisión, pero dentro de un mareo en el que la idea de verdad ha mantenido una posición decisiva. No es ajeno al caso, desde luego, el que la vigencia de esa concepción compartida (se cree comúnmente en la verdad, aunque sea crea separadamente en verdades antagónicas) se haya visto alterada fuertemente por el movimiento romántico, primero, y por diversas formas de antihumanismo después.

De cualquier manera, a efectos de la presente exposición, daremos por hecho que cabe analizar el caso a la luz de una contraposición teórica entre las propuestas de lo que se suele considerar las vigencias culturales más operativas de la cultura digital, y las bases de una concepción de la vida humana más clásica, muy generalmente compartida y que ha estado a la base del enorme desarrollo de la civilización contemporánea, pero que es también responsable, en cierto modo por su carácter abierto y dialogal, de las formas de desarticulación conceptual que ahora experimentamos con diversos grados de perplejidad y de angustia.

La cultura digital extiende una serie de prejuicios, en ocasiones no suficientemente explícitos, como, por ejemplo, el hábito de olvidar la diferencia entre información y conocimiento, la tendencia a identificar lo virtual y lo real, la condena a la inexistencia de lo que no es insistentemente manifiesto, etc., cuya efectividad práctica tiende a socavar, de manera casi nunca explícita, los fundamentos de la 
concepción clásica sobre las relaciones entre la realidad y las distintas formas del saber, a poner entre paréntesis lo que se podría llamar, con expresión de Burtt (1940), los fundamentos metafísicos de la ciencia moderna.

La tesis que trataré de sostener, de manera tan matizada como me sea posible, es que la crisis de las instituciones críticas vigentes antes de la era digital (me refiero tanto a las universidades como a las academias, las editoriales o los periódicos) no se ha corregido (todavía) con suficiente eficacia por instituciones de la nueva era. Ello supone asumir que cabe esa sustitución, lo que se puede discutir si se hace una evaluación más pesimista respecto de las tesis que a continuación se enumeran.

\section{Era digital y sociedades de masas}

La era digital ha servido para potenciar los caracteres negativos de lo que se ha llamado las sociedades de masas. Cierto es que esas sociedades han sido descritas de muy diversas maneras, pero si escogemos los rasgos en los que han coincidido la mayoría de los críticos, podremos ver que esas cualidades permanecen y se han intensificado en la era digital.

Las sociedades de masas, tanto en los análisis más negativos como en los que no lo son tanto, funcionan con acuerdo a pautas de comportamiento individual que son muy distintas a las que determinaban la conducta individual en las sociedades preindustriales, las que Oakeshott (2008) ha llamado sociedades de vínculos comunales. Lejos de depender casi exclusivamente de tradiciones y de reglas morales cálidas, tienden a disolver los vínculos familiares y sociales establecidos de manera casi inmemorial para comportarse con arreglo a normas en las que cualquier especie de novedad, lejos de ser un inconveniente, se convierte automáticamente en un estímulo casi irresistible2. En ellas importa mucho más lo que se dice, por ejemplo,

\footnotetext{
${ }^{2}$ No creo que esa tendencia a la novedad pueda estimarse de plano como una característica negativa, puesto que es obvio que hay algo en nosotros que nos lleva a "superar" y/o "cambiar" la naturaleza, a crear nuevas realidades culturales y tecnológicas. Me he ocupado de este tema en particular en un artículo a dos manos (González
} 
a través de los medios de comunicación, que lo que se hace, de forma que la opinión ajena y las modas se convierten en formas de legitimación de conductas tan importantes como cualesquiera de las vigentes en el seno de una sociedad determinada, de forma que el recurso a la extravagancia o la innovación ya no puede ser objeto de una censura por principio, por lento que haya podido ser, en la práctica, ese proceso de tolerancia o aceptación social de lo estridente o lo anómalo. Esta falta de sumisión a los principios de comportamiento establecidos es lo que convierte a estas sociedades en sociedades post-tradicionales.

Claro es que el desarraigo respecto a lo comunal trae consigo otras formas de dependencia, un fenómeno que se ha deserito muchas veces como el nacimiento de una nueva sumisión hacia la moda y los hábitos del consumo. Muchos sociólogos han descrito, hace ya décadas, ese estado de cosas sumariamente diciendo que los jóvenes dejan de parecerse a sus padres para hacerse indistinguibles de sus amigos.

En lo que se refiere al papel de los medios clásicos, y en especial de las televisiones, se ha hecho corriente afirmar que esos medios parecen (me temo que parecen más de lo que es) haber perdido parte de su influencia para cederla a manos de las numerosas redes sociales que, sean lo que fueren, no pueden reducirse a meras prolongaciones de formas de sociabilidad tradicional. En cualquier caso, es evidente que estamos asistiendo ya a una situación en que la televisión clásica, la red por antonomasia, ya un poco clásica también, y las redes sociales van a converger de manera que el conjunto se torne los suficientemente espeso como para hacer distinciones nítidas entre las diferentes vías de información y entretenimiento.

Las sociedades de masas se han descrito casi unánimemente como sociedades muy manipulables en los que la autonomía del individuo se ve seriamente amenazada. Esta dependencia de decisiones que son ajenas a la capacidad del individuo medio se considera por lo general seriamente potenciada en la era digital, aunque, sin duda, la multiplicación, realmente enorme, de las fuentes de información ha tenido efectos que no apuntan necesariamente en esa misma dirección, y no

Quirós J.L. y Puerta J.L. 2009(b)), pero tampoco puede iǵnorarse que siempre cabe la distinción entre innovaciones creativas y valiosas y mera retórica, propaganda, manipulación o superchería. 
faltan los sociólogos y los comunicadores que ven en esta clase de críticas un lamento por la pérdida de influencia y la crisis económica de viejas y grandes empresas de comunicación clásicas. De hecho, en este debate preciso se puede ver una reformulación de la supuesta dialéctica entre élites y hombres masa que atraviesa, por ejemplo, la exposición orteguiana al respecto y que, para la visión más pretendidamente progresista supone poco más que la queja por la pérdida de poder de las aristocracias que se expresa en expresiones de uso corriente como tiranía de la mayoría. Esta posición contrasta, aun compartiendo muchos de sus aspectos descriptivos, con el llamado enfoque crítico de la Escuela de Fráncfort que contempla las sociedades de masas como fruto de una alienación que se pone al servicio de la cultura del consumo promovida por el capitalismo.

La paradoja de buena parte de estos análisis consiste en que, aunque se reconozcan como ciertos los efectos negativos del desarrollo tecnológico e, incluso, del progreso económico, no es fácil negar los efectos positivos de esa clase de cambios que se abren paso a través del reconocimiento del pluralismo y de la democracia e igualdad política. A los efectos de este primer apunte, lo esencial es señalar que apenas alguno de los fenómenos que se describen en la literatura sociológica como característicos de la cultura diǵital carece del correspondiente antecedente en las sociedades de masas y en las características básicas de la vida humana en las sociedades en que se han asociado el capitalismo y la libertad política. Que el impulso de la tecnología digital, que por primera vez es, realmente, una tecnología universal, y tan de masas como se quiera, ha acelerado y agudizado todas esas características es algo que apenas merece discusión, según entiendo.

La influencia de la digitalización en nuestras vidas ha operado, por tanto, sobre un tipo de sociedades en las que ya era muy determinante todo lo que se ha solido calificar como formas de deshumanización, un marbete probablemente discutible y excesivo que ha dependido además de debates intelectuales muy influidos por el trauma europeo de las dos grandes guerras del pasado siglo, sobre todo en la forma precisa del criticismo político y cultural de las filosofías de la existencia. Sin embargo, en la medida en que esa caracterización pueda resultar pertinente, no hay duda de que la era digital ha prolongado esos efectos, 
hasta el punto de que han menudeado los informes más o menos alarmistas sobre algunos de los supuestos efectos más perniciosos de los entornos digitales en nuestras capacidades cognitivas y relacionales (supuestos efectos sobre la capacidad de lectura y/o reflexión, incluso sobre una disminución perceptible del nivel medio de inteligencia) ${ }^{3}$.

\section{Categorías intelectuales del mundo digital}

El efecto más disruptivo de las categorías intelectuales que habitualmente se dan por sentadas entre los teóricos y apologistas de la cultura digital consiste en que deja en la penumbra, como cuestiones en cierto modo irrelevantes, ciertos compromisos epistémicos y morales que resultan básicos en lo que se ha llamado cultura humanista o tradicional, pero también en la cultura científico-tecnológica desde un punto de vista académico. Efectivamente, las ideas de conocimiento y verdad, el valor de la libertad intelectual y moral, el imperativo de objetividad, la idea de deber, por citar lo decisivo, aparecen como ideas que no resultan necesarias para mantener en vigor los progresos económicos y tecnológicos que se consideran irrenunciables y característicamente humanos.

Desde Nietzsche, al menos, se había hecho bastante común poner en solfa esta clase de ideas de difícil justificación y de fácil crítica, pero lo que seguramente resulta demoledor no es el que un autor más o menos influyente filosofe acerca de la posible carencia de justificación de cualquier significado último de las cuestiones metafísicas, sino que, aunque se ignoren en todas sus complejas dimensiones, el equivalente

\footnotetext{
${ }^{3}$ Sobre este punto puede verse, por ejemplo, un texto muy citado de Nicholas Carr, y su libro (2017) que puede inscribirse en una tradición antitecnológica bastante vetusta de la que me ocupé en González Quirós (1998 (b)). Un informe muy reciente sobre el retroceso de lo que se conoce como efecto Flynn (el incremento habitual de las puntuaciones de cociente intelectual), puede verse en B. Bratsberg y O. Rogeberg (2018) que en su estudio atribuyen la interrupción (turning point) de ese crecimiento a factores ambientales como podría ser el cambio en los hábitos de lectura de la población examinada. Encuentro discutible la afirmación de que se lea menos, aunque me parece evidente que se lee de otras maneras y, sobre todo, se leen cosas distintas, en contenido y en soportes, a las que han facilitado durante siglos los contenidos de la educación básica y que sirvieron también para soportar la investigación y la ciencia.
} 
José Luis González Quirós

de esas ideas, digamos, disolventes, se conviertan en valiosos principios prácticos de conducta para una amplia mayoría de personas. Eso había empezado a suceder en sectores más o menos minoritarios a través de la literatura y las artes, de manera progresiva con el cine y las televisiones, pero la difusividad acrítica propia de los canales de la sociedad digital ha convertido esas pautas de comportamiento en formas habituales de comprensión, juicio moral y conducta personal.

En mi opinión, la causa específica de esa difusión está en el hecho de que las teenologías digitales han hecho más que nadie para que las dificultades tradicionales de comunicación, asociadas a categorías básicas de la realidad, como el espacio y el tiempo, hayan tendido, sencillamente a desaparecer, haciendo que en el imaǵinario popular se desdibuje por completo cualquier diferencia entre la realidad efectiva y la realidad deseada. Dicho de manera paradójica, la tecnología que es, en su base más honda, estrictamente lo contrario de la magia, se ha convertido en un proveedor social de toda clase de fantasías. Por supuesto que este efecto no se le puede atribuir en exclusiva a la revolución digital, pero, como veremos, la digitalización ha hecho más que nadie para que la distancia entre la realidad y sus imágenes, aunque sean específicamente distorsionadas, tienda a desaparecer casi por completo.

Se trata de un efecto multiplicador que, por ejemplo, sirve para intensificar grandemente usos ya conocidos, al tiempo que los transforma de manera menos perceptible que radical. Pensemos, por ejemplo, en el consumo de pornografía: seguramente desde la invención misma de la escritura esta se pudo emplear para difundir contenidos salaces, lo que Quevedo llamaba literatura para una sola mano, pero la fotografía y el cine han multiplicado las formas posibles de este tipo de narrativa que, con Internet, se ha convertido en uno de los mayores usos de la red, sino el mayor, cosa que es discutible hubiese podido pasar en el mundo del papel: el sexo que es una función rotundamente biológica se convierte así en un contenido digital ${ }^{4}$.

\footnotetext{
${ }^{4}$ Ya he citado en otras ocasiones el caso de Denise calls up (Hal Salwen, 1995) una película que es a la era digital, y en especial a las relaciones personales en este contexto, lo que fue Tiempos modernos (Charles Chaplin 1936) 1respecto a la mecanización.
}

Naturaleza y Libertad. Número 11, 2019. ISSN: 2254-9668 
Los efectos morales y políticos de esta clase de desvanecimiento están todavía por experimentarse en toda su magnitud, salvo que, por una revolución epistémica y moral, que ahora no se adivina, se puedan revertir esta clase de consecuencias. La cultura occidental se había venido deshaciendo de sus guías metafísicos ya desde hace tiempo, quedaba en píe, al menos en teoría, la verdad científica, pero hace tiempo que la propia ciencia ha dejado de ser universalmente considerada como una especie de monumento colectivo a la verdad. Cabe pensar, incluso, que la ciencia deje de representar un valor social significativo en la medida en que se tenga por un tipo de actividad escasamente respetuosa con el peso de las ortodoxias establecidas, la ciencia al modo de Feynman, por ejemplo, y que en la era digital tiendan a imponerse valores más neutros y de apariencia inobjetable como los que no raramente promueven las grandes corporaciones teenológicas 5 .

El punto esencial, es menester insistir en ello, es el que se relaciona con la idea de verdad, puesto que el papel que juega en la vida humana, en la medida en que los seres humanos somos seres pensantes, no se puede reducir a un problema metafísico más o menos paradójico o irresoluble: lo contrario significara necesariamente no solo considerar que, de hecho, la posverdad ha llegado, como mínimo, a los periódicos y a la política convencional, sino dar por bueno que lo haya hecho y no caer en la cuenta que ese desentendimiento con una idea fuerte de verdad puede acabar destruyendo cualquier atisbo de libertad intelectual y de racionalidad en la vida colectiva.

\section{Los eclipses de la verdad}

La digitalización ha tenido y está teniendo efectos enormes sobre la idea de verdad. La metáfora práctica en la que, en cierto sentido, se

\footnotetext{
${ }^{5}$ En este sentido es particularmente interesante escuchar el testimonio de James Damore, un ingeniero despedido por Google por defender ideas que la empresa consideró "inadecuadas". Damore afirma que Google actúa tratando de minar la ideología de derechas en favor de la ideología de izquierdas a través de ciertas prácticas tanto en el interior de la empresa como hacia afuera, por ejemplo, penalizando videos con orientación conservadora/republicana y favoreciendo los videos de orientación demócrata.
} 
han apoyado buena parte de las definiciones de la verdad, es la distinción entre original y copia, una distinción que pierde completamente su sentido en el mundo digital. La información se ha desligado completamente de sus soportes, se ha desrealizado, y al hacerlo ha tendido a desdibujar la existencia misma de su referente, de una realidad original respecto de la cual toda información, todo discurso, habría de aspirar a ser una copia fiel, tan minuciosa como sea posible.

En el universo digital tal tipo de distinciones tienden a perder completamente su significado. La copia digital pierde su sentido referencial y empieza a ser, dada su identidad lógica o numérica con lo que reproduce, una nueva realidad que, a diferencia de la realidad de partida, es infinitamente versátil y manipulable, es decir, preferible a la rigidez original de lo real a la mayoría de los efectos, lo que puede hacer que el segundo escritor del Quijote que imaginó Borges tenga muy a la mano su tarea. El lector no solo es autor a título imaginario e interpretativo, sino que puede pasar a serlo efectivamente de cualquiera de las infinitas variables a que se puede someter un documento tan plástico.

La apertura a cualquier manipulación oculta automáticamente la referencia a un valor objetivo ajeno al mismo texto, que se refiera a algo esencialmente distinto, de forma que todo documento digital puede ser estrictamente novelesco, si no se toman las garantías intelectuales que, de hecho, no se están tomando de ninguna manera. Ahora mismo es casi imposible saber si un texto en red es realmente el que responde a la intención original de su autor porque los sellos de autenticación en ese mundo ni son todavía tan eficaces como lo han sido en el mundo impreso (en el que, por supuesto, han cabido las falsificaciones) ni, sobre todo, se echan suficientemente de menos.

A la par que se produce la pérdida del sentido de la realidad que aparece implícito en la distinción entre original y copia, también se desdibuja la diferente función del autor y del lector, lo que se ve con mucha facilidad en ese intento tantas veces desesperado de conseguir la participación de los espectadores en cualquier clase de actos. Es como si una cierta conciencia de la futilidad del creador pudiera atenuarse mediante las respuestas del público, con frecuencia enteramente irrelevantes, pero que contribuyen a la ficción de que ha existido una interacción, una especie de realidad dialogada. 
El caso es que no hay manera de ocultar que la supuesta originalidad de cualquier creación ha quedado casi completamente sepultada tanto por la enorme abundancia de voces y funciones similares que hacen que cualquiera deje de ser único, como por el hecho de que los lectores dejen de ser puros receptores y se conviertan en una especie de hermeneutas, normalmente sin oficio alguno. En fin, hace falta ser muy fuerte, para no sentirse anonadado por la abrumadora y confusa oferta de información disponible, o peor aún por la amenaza que supone poder gozar de muchísima información olvidando que, como decía malévolamente Ortega, se puede ser tonto en muchas lenguas, aunque tengamos acceso a millones de fuentes.

\section{Verdad y dinero}

La mayoría de nuestros conceptos ${ }^{6}$, sea cual fuere su origen, se ven sometidos a un intenso trato práctico y acaban adquiriendo un significado general, que es el primero del que hay que partir cuando nos decidimos a pensar sobre ellos, a sopesar lo que significan, lo que nos dicen y también lo que acaso nos ocultan.

El concepto de verdad no plantea demasiados problemas en la práctica, porque nadie que esté en su sano juicio preferirá lo falso a lo verdadero, lo dudoso a lo cierto, la mentira a la sinceridad. Ahora bien, la cosa se puede complicar mucho a nada que reparemos en dos dimensiones de la idea de verdad, en su transparencia práctica y en sus paradojas teóricas, pero todavía más si nos paramos a pensar en el destino que le espera a la categoría de verdadero en una sociedad que posee los medios necesarios para multiplicar, prácticamente hasta el infinito, cualquier versión o apariencia, y, por supuesto, cualquier falsedad, especialmente cuando se hace, y se hace extraordinariamente a menudo, para que puedan pasar por verdaderas afirmaciones que distan muy mucho de serlo.

Para verlo más de cerca, usaré una analogía entre la verdad y el dinero. En el caso del dinero disponemos de instituciones -los Bancos-

\footnotetext{
${ }^{6}$ En este apartado sigo casi a la letra un artículo que escribí a petición de Gonzalo Mendoza, director de la Escuela de Filosofía en Madrid, y que se publicó el 2 de junio de 2014 en el blog que la Escuela de Filosofía en El Confidencial con el título de "Nadie en su sano juicio prefiere lo falso a lo verdadero... ¿̇De verdad?".
} 
cuya misión principal consiste, literalmente, en multiplicar el dinero aumentando su velocidad de circulación, haciendo que el depósito de uno se convierta en moneda circulante para otro, para muchos. Naturalmente que ese es un proceso con riesgos, y que, precisamente por eso está sometido a diversas formas de regulación que tratan de conseguir que el dinero que circula a partir de depósitos previos sea tan fiable y preciso como el dinero depositado que de alguna forma lo respalda, y que el conjunto del proceso de multiplicación no resulte inverosímil o insostenible. Con una unidad cualquiera se consigue una especie de milagro de los panes y los peces sin que nadie sospeche del artificio porque, habitualmente, es beneficioso para la economía de todos.

Vayamos ahora al fenómeno de circulación del conocimiento, de lo que supuestamente tenemos por verdadero. Las industrias de la cultura y de la información, como en otro tiempo las iǵlesias, los editores o las universidades, funcionan como auténticos multiplicadores de la verdad, expandiendo casi de manera infinita el conocimiento que se supone verdadero y válido. Las verdades se convierten así en una mercancía capaz de producir efectos benéficos por todas partes y por mucho tiempo. La diferencia es que nuestro sistema de regulación del dinero, con todas sus deficiencias, es mucho más poderoso y preciso que cualquier proceso equivalente que podamos imaginar o suponer para garantizar el valor de las verdades en circulación.

Siempre que tengamos un dólar o un euro en las manos sabremos lo que se puede hacer con ellos, salvo que ese día haya estallado una crisis universal, y el pánico se adueñe de las calles. Por el contrario, ya podemos tener en las manos la más exquisita y sólida de las colecciones de verdades, una fortuna en conocimiento, que nunca está del todo claro qué podríamos hacer con ella. No hemos encontrado la manera fiable y sencilla de convertir el capital de verdades en moneda de uso inmediato, eficaz y universal. Me refiero, en primer lugar, al hecho, bastante obvio, al que hacíamos referencia al comienzo de estas páginas, a saber, que el conjunto actual de los seres humanos vivos está radicalmente dividido respecto a verdades supuestamente fundamentales, y, en segundo lugar, a que muchas de las verdades más hondas y útiles, como las verdades de la ciencia, por ejemplo, no pueden ser 
normalmente manejadas por el común de los mortales sin que se nos exponga a riesgos en verdad disparatados.

Vuelvo ahora a la afirmación inicial que decía que la idea de verdad es transparente, una manera de subrayar que por más que se nos diga que una afirmación es verdadera, por más que lo firmase el presidente del correspondiente Banco de verdades, jamás podríamos distinguir a primera vista una sola verdad del inmenso conjunto de falsedades muy similares y escasamente distinguibles de ella- que se pueden pensar y decir. Toda forma de conocimiento está rodeada de inmensos racimos de ignorancia, con un aire de familia muy parecido al del saber verdadero, sin que sea tarea sencilla distinguir el grano de la paja, y esta situación está especialísimamente presente en la era digital. Para poder hacer esto con ciertas garantías, para poder distinguir con alguna seguridad la verdad de lo que no lo es, se precisa poseer una cualidad que no tiene paralelo en el mundo del dinero: hace falta ser sabio, o experto, si se prefiere, en un concreto tema para que se pueda sostener, a título propio, si una afirmación cualquiera es verdadera o falsa. Esta situación no tiene paralelo en el mundo del dinero porque para manejar un euro o un millón de ellos no hace falta ser millonario: todo el mundo acepta sin rechistar la validez del dinero.

Pues bien, a pesar de todo cabe afirmar que la analogía entre el valor del dinero y el valor de la verdad no está descaminada por una razón fundamental: porque las construcciones simbólicas que se supone han de ser verdaderas acaban funcionando igual si lo son que si no lo son, acaban creando su propia verdad. De manera que, a muchos efectos, andar preguntando si algo que se dice, se cree, se afirma o se supone, es realmente verdadero, se podría asemejar bastante a la conducta del que ante cada euro acudiese al Banco Central europeo a certificar si esa moneda tiene suficiente respaldo. De hecho, la conducta de la mayoría con la información es estrictamente equivalente a su conducta con el dinero: lo toman, lo cambian y lo consumen, sin mayores preocupaciones. En el caso de la verdad pasa, además, que la aceptación general no desgasta el valor que se le supone, sino que, en cierto modo, lo certifica y lo aumenta en la medida en que pasa a formar parte de lo muchísimo que se da por supuesto, precisamente porque se repite de manera infinita. Se trata de una situación ciertamente curiosa porque, de ninguna manera la aceptación muy 
extendida de algo resulta ser una garantía fiable de su valor como verdad. Piénsese, por ejemplo, en la enorme distancia que existe habitualmente entre lo que la mayoría de la gente cree que afirma la ciencia (en dietética, en medicina, en física o en economía) y lo que realmente resulta ser cierto, una situación que retrató sarcásticamente Truesdell (1975) cuando, a propósito de la historia de los orígenes de la teoría cinética de los gases, dijo que en cuestiones de la ciencia, la mayoría siempre se equivoca.

No es un pequeño mérito del mundo contemporáneo que hayamos construido un sistema tan sólido como para poder olvidarnos de inquirir sobre sus fundamentos, y que eso valga casi tanto en cuestiones de moral como de economía o de ciencia. Esto no nos libra del todo de una preocupación que resulta fundamental, a poco que se medite: aparte de usar sin demasiadas cautelas la idea de verdad, cंdeberíamos preguntamos un poco más a fondo por ella? Si acudimos a los filósofos veremos que nos aconsejarán algunas precauciones elementales, pero que tampoco poseen ninguna receta especialmente efectiva. Podríamos resumir la cosa del siguiente modo: una cosa es constatar que, de hecho, la verdad importa relativamente poco en la sociedad en que vivimos, que el lugar de la verdad está plenamente ocupado por las tecnologías de la información, y que la demanda rigurosa y efectiva de verdad es prácticamente irrelevante, y otra cosa muy distinta es plantearse la cuestión de si la idea de verdad debiera importar, o si es un concepto del que podríamos prescindir sin mayores temores.

Lo que parece suceder es que la mayoría de la gente se conforma de manera habitual con una verosimilitud tolerable, aunque sea muy tenue, y que ese mismo público tiende a conformarse también con esa ausencia de libertad "suave, razonable y democrática", contra la que tronó Marcuse en los años sesenta. La cuestión es, finalmente, muy simple: ¿consentirán las sociedades tecnológicas del futuro espacios de discusión en los que se pongan en cuestión sus fundamentos? Puede parecer una pregunta abstracta, pero responderla de uno $\mathrm{u}$ otro modo tendrá repercusiones que acaso pudieran llegar a ser incontrolables.

La insólita frecuencia con la que se entroniza como una verdad vigente a mentiras precisamente manufacturadas, lo que ahora se llaman fakes, nos lleva a tener que preguntarnos si resultará suficiente el consejo rortyano aplicable a esta clase de cuestiones, "preocúpate 
de la libertad que la verdad se cuidará de sí misma”, un lema que acaso sea excesivamente ingenuo para los tiempos que vivimos.

\section{La paradoja de la tecnología}

En la sociedad digital se ha hecho especialmente patente esa curiosa contradicción, a la que nos hemos referido líneas arriba, entre la realidad, racional y científica, de la tecnología (en su fase de invención) y sus efectos sociales (en su momento de uso). La tecnología que solo puede triunfar cuando se ponen en funcionamiento posibilidades efectivas de la más dura realidad, esa tecnología que supone una verdadera ascesis intelectual, un esfuerzo denodado por acertar, un trato despiadado con las dimensiones efectivas más radicales que se pueden alcanzar en lo real, se convierte cuando se torna en herramienta, en algo que se usa, por supuesto sin comprenderla en la inmensa mayoría de los casos, en aproximadamente lo contrario, en un camino real a la fantasía, a la más desbordada imaǵinación. La imaginación, en efecto, juega un doble papel en la tecnología: en primer lugar, está en los orígenes de su invención, cuando la fantasía de volar, por ejemplo, se aviene a negociar sus posibilidades con las condiciones de la realidad física y, en ese sentido, la tecnología es hija suya, pero la imaǵinación no es nunca su único progenitor, porque en ningún caso es posible la tecnología a partir de la mera fantasía: se precisa siempre la disciplina del que se deja los ojos y la cabeza tratando de entender cómo son las cosas que la harán posible y qué es lo que puede hacerse a partir de ellas ${ }^{7}$. Pero una vez que la tecnología está disponible, que se ha comprobado que funciona, que ha encontrado una vía para acceder a lo que antes no era posible, que es capaz de modificar de alguna manera la realidad que está a nuestra disposición, la tecnología entra en otro reino en el que la fantasía vuelve a jugar un papel decisivo.

$\mathrm{Al}$ convertirse en herramienta, en un modo de hacer, entran en juego las formas posibles de explotación de esa nueva posibilidad, y la tecnología deja de depender de las limitaciones de la realidad física para pasar a ser el escalón el que se apoya un tipo muy distinto de fantasía, la que provoca la ambición mercantil, el uso generalizado y

${ }^{7}$ Puede verse González Quirós (2013 (a)). 
las ventajas de todo tipo, y muy en especial las económicas, que se pueden conseguir. De todas formas, incluso aquí la tecnología tiene que lidiar con nuevas realidades, con limitaciones de distinto tipo, pero no menos efectivas, de forma que no se puede reducir todo a la loca imaginación, salvo que se quiera sufrir una severa y dolorosísima derrota.

Sin embargo, y una vez que esas nuevas dificultades se han convertido en circunstancias viables, lo que ocurre es que los usuarios contemplan no sin asombro como pueden hacerse cosas que antes se tenían imposibles, que lo eran muy efectivamente, y esa consideración opera como un eatalizador de toda clase de imaginaciones, de una serie inagotable de rupturas con las limitaciones más comunes, con el espacio, con el tiempo y con cualquier forma de ignorancia o de misterio. El usuario que maneja su teléfono inteligente, y que paga por ello cantidades asumibles que no le suponen, al menos en apariencia, ninguna limitación importante de sus capacidades de elegir y de tomar decisiones, empieza a manejar posibilidades que nada tienen que ver con las limitaciones tradicionales que le ofrecía la realidad, puede hablar con la China con solo tocar un botón, comprase una gabardina con un esfuerzo no mucho mayor, o escuchar su música preferida sin moverse ni para usar el mando a distancia. Las tecnologías se parecen mucho a una varita mágica y es casi imposible que el mero uso deje siquiera imaginar las inmensas dificultades conceptuales y físicas que los creadores e inventores han debido superar para hacer real esa clase de imposibles previos. El resultado de todo ello es que cierta idea distante y capaz de producir admiración e inteligencia, pase a un segundo plano, se vea eclipsada por meras imágenes, que, a infinidad de efectos, la verdad deje de tener cualquier relevancia significativa, y que las posibilidades y los deseos tiendan a confundirse en una especie de bucle infinito. En este sentido, las tecnologías digitales funcionan como gigantescos sistemas de apartamiento de la realidad inmediata, como dispositivos que nos evitan la distancia crítica, y el acercamiento riguroso, respecto al significado último de las cosas con las que nos tropezamos en la vida.

Mientras repaso estas líneas se ha producido una noticia realmente terrible que puede anotarse en favor de lo que pretendo decir, aunque 
haya que tomarla con la menor truculencia posible. Un padre madrileño olvidó a su hija de dos años en el coche, y el calor del verano la hizo morir deshidratada. Al parecer, cuando iba a sacar a su hija del coche para dejarla en la guardería recibió una llamada telefónica del trabajo que le hizo olvidar la rutina habitual que cada día empleaba para dejar a su pequeña a buen recaudo, tras aparcar el coche para dirigirse luego a su oficina. Esa celeridad digital y ese trabajo que ha roto con las limitaciones de cualquier horario han hecho posible que un padre seguramente ejemplar y amantísimo de su hija se olvide de ella, que se haya podido apartar de la realidad más humana e inmediata arrebatado por las urgencias de una segunda realidad superpuesta pero capaz de ocultarle la esencial. Se trata, desde luego, de un accidente tremendamente desafortunado, y sería absurdo hacer cualquier demagogia con él, pero el caso es que la desmedida intromisión de las tecnologías, y de las urgencias económicas y laborales que ellas traen y con ellas vienen, hayan hecho posible algo bastante difícil de imaginar en una persona seguramente responsable $y$ atenta a sus obligaciones que se moviese en un entorno predigital.

Es indiscutible que la era digital nos hace relacionarnos con la realidad a través de unas capas que la ocultan y domestican, pero que, precisamente por eso, también pueden arrebatarnos los lazos naturales con formas de la realidad que nunca desearíamos abandonar, si nos lo planteásemos de manera reflexiva. Lo importante no son los ejemplos prácticos de esa desrealización, o de la sustitución de la realidad inmediata por sus ersatzs digitales, que se podrían multiplicar sin demasiada dificultad, sino el potencial destructivo que podrían implicar modos de pensar troquelados en entornos tecnológicos respecto a nuestra relación con lo que primariamente es, con lo que efectivamente sabemos y con lo que debiéramos hacer.

Una idea del conocimiento y de la misma verdad como un proceso de construcción, una forma de pensar cuyos orígenes son muy anteriores a la era digital, puede verse muy reforzada en esta clase de contextos en los que todo parece consecuencia de un programa, de un artificio, de técnicas y efectos buscados, un universo efímero y barroco en el que se puede llegar a conseguir que la realidad se vea efectivamente anonada, arrebatándole, por paradójico que parezca, cualquier función precisa en las tareas del entendimiento. 
En el plano social y político seguramente tengamos que enfrentarnos también con entornos que desmientan los parámetros tradicionales para pensar en las formas más correctas y deseables de diseñar los espacios públicos, de pensar las relaciones entre la sociedad y el Estado, entre los ciudadanos y los poderes de control, sean estatales o mercantiles.

Podría ser que, a largo plazo, estemos caminando hacia una economía sin escasez, si tal cosa cabe sin contradicción, a la manera como vemos florecer empresas que no reparten beneficios con su actividad, sino con las expectativas que generan, un fenómeno que tampoco es de ahora mismo, pero que está registrando en estos momentos sus casos más espectaculares. El dinero mismo parece estar entrando en contextos de regulación muy distintos a los tradicionales, y hasta es posible que los Estados vean en riesgo sus atribuciones en este terreno sin acertar a evitarlo, pero también en muchos otros campos de la actividad que van a ser muy distintos de lo que han sido como consecuencia de aplicaciones digitales que ahora ya empezamos a adivinar.

No me parece inteligente ni honesto sembrar dudas sobre la capacidad humana de resolver esa nueva clase de problemas, a medida que vayan surgiendo, ni tampoco confundir la tarea del pensador con una crítica demoledora de cualesquiera posibilidades de cambio que nos brindarán las tecnologías. Dejarse llevar por cualquier tecnofobia me parece un error de enormes consecuencias, pero eso no implica cerrar los ojos a las amenazas ciertas que pueden comportar la implantación incesante de novedades, y las que promueven los avances digitales no son pequeñas.

En el campo de la política me parece sobradamente obvio que las posibilidades de los males gobiernos, y siempre serán mayoría, para manipular a las opiniones públicas no dejan de crecer. Este tipo de riesgos se hacen más graves a medida que las sociedades en que vivimos pueden logar cotas de seguridad y bienestar bastante altas, para mayorías muy amplias, todo lo cual favorece que las lecturas críticas de cuanto sucede se vean atenuadas, y puedan terminar por verse consideradas como chaladuras, en tanto se acabe por consagrar la impresión de que vivimos en el mejor de los mundos posibles, aunque eso pueda parecer todavía bastante utópico. 
En cualquier caso, nuestras sociedades pueden evolucionar hacia formas de convivencia que no faciliten en absoluto una democracia popperiana, con discusión idealmente racional y posibilidades de destitución pacífica de los gobiernos, en la medida en que los debates no sean demandados por ciudadanos dispuestos a conocer la verdad de cada caso, o porque se conviertan en virtualmente imposibles y/o se declaren innecesarios (lo que de alguna manera anunciaba el supuesto advenimiento inmediato de lo que Fukuyama (1992) denominó el fin de la historia, bien sea porque se haya perdido la referencia de cualquier tradición, bien porque cualquier verdad termine sepultada por la catarata de novedades y reducida a curiosidad en bibliotecas digitales que carezcan de la debida vitalidad, que existan pero sin apenas influencia sobre la marcha efectiva de las cosas. He dicho pueden, pero no que necesariamente haya de ser así.

\section{Posibilidades mercantiles y horizontes intelectuales}

Lo que seguramente sucede ahora mismo es relativamente sencillo de explicar, a mi modo de ver. Ocurre que las inmensas posibilidades que se han abierto con las tecnologías digitales se han dedicado en un porcentaje abrumadoramente alto a explotar posibilidades mercantiles, en lugar de a poner en marcha instrumentos intelectuales mucho más afinados de los que han sido posibles, y efectivos, en la era de la imprenta. Empezaré de nuevo con un ejemplo, hoy en día, y salvo que yo ande muy despistado, no es nada fácil conseguir en la red ediciones de textos clásicos con la garantía crítica y científica que siempre han sabido dar sellos editoriales tradicionales bien conocidos por todos. $\mathrm{Si}$ se tiene en cuenta que hoy en día se podrían hacer cosas mucho más efectivas y rotundas que una clásica edición crítica de un texto ${ }^{8}$, se comprenderá que el desarrollo de esas perspectivas nos parezca gravemente atrasado.

\footnotetext{
${ }^{8}$ Hace ya más de una decena de años que, junto a Karim Gherab Martín (2006), me ocupé extensamente de algunas de las posibilidades que ofrecía el entorno digital para alcanzar una serie de mejoras muy de fondo en los distintos ámbitos de cultivo del conocimiento: nos parecían muy evidentes, pero seguramente pecamos de optimistas.
} 
Naturalmente que diversos grupos de investigadores han puesto en marcha portales y repositorios de calidad, pero eso representa una pequeñísima parte de lo que se podría hacer y no se hace. Tal vez el fondo del asunto esté en las inercias morales e intelectuales de los respectivos colegios e instituciones a los que ya hemos aludido (las academias, las bibliotecas, las universidades, la prensa, etc.), y que sea necesario que pase más tiempo para que se cambien hábitos excesivamente arriesgados en educación, en ciencia y en pensamiento.

Lo que no ofrece dudas es que la magnitud del problema que hay que afrontar para poner al día en cuanto a posibilidades digitales a las instituciones críticas a las que hemos aludido no cesará de crecer con los años, lo que no implica que no se acabe por encontrar el camino áureo para lograrlo. Algo parecido, por ejemplo, a un uso intelectual de las tecnologías de blockchain podría ponerse en marcha en un futuro no muy lejano evitando de manera definitiva el que se puedan alterar determinadas evidencias o que se pueda dar gato pseudocientífico por liebre de conocimiento verdadero.

No será fácil evitar que esas herramientas pretendan consolidar una especie de orden de verdades indiscutibles, pero no debiera ser menos evidente que podrían ayudar a que no sea razonable atender, no lo es de hecho, a los que aseguren, por ejemplo, conocer los procedimientos necesarios para alcanzar la regeneración del cartílago rotuliano o afirmen seriamente que Colón nació en la Cataluña eterna, y lindezas semejantes.

Por supuesto que ahora mismo, como se ha hecho siempre, pueden llevarse a cabo esta clase de filtros y discriminaciones, pero no con un éxito inenarrable, y cabe esperar que aprendamos a usar las facilidades del entorno digital para mejorar la eficacia de los análisis críticos, defendiendo al tiempo la verdad de las cosas y la libertad del entendimiento. Tiene que ser posible que, partiendo de bases sólidas, se pueda contar con medios rotundamente eficaces para combatir vicios demasiado frecuentes en la literatura académica, como el plagio, la verborrea, la simulación de haber consultado fuentes que no se han trabajado, el olvido de argumentos y datos decisivos, o la simple falsificación de hechos o referencias, de forma que el trabajo intelectual y de investigación pueda consaǵrarse, efectivamente, a plantea las dudas razonables y las distintas posibilidades de abordaje, realmente nuevas, 
que quepa ensayar sobre cualquier asunto realmente de interés. Este uso ascético de las tecnologías ha de corresponder a una etapa más consagrada a fortalecer ideales que satisfacer deseos, algo que ahora mismo está claramente fuera de foco en los desarrollos más poderosos de las tecnologías digitales, pese a que se las llame, con tanta frecuencia como escasa discreción, tecnologías del conocimiento.

\section{Bibliografía empleada}

B. Bratsberǵ y O. Rogeberg, "Flynn effect and its reversal are both environmentally caused" accesible en https://doi.org/10.1073/pnas.1718793115 (2018)

J. L. Borges, Pierre Menard autor del Quijote, cuento incluido en varias ediciones de su obra literaria.

G. Bueno, Televisión: Apariencia y Verdad, Barcelona, Gedisa, 2000.

E. A. Burtt, E.A. Los fundamentos metafísicos de la ciencia moderna, Buenos Aires, Sudamericana, 1940.

N. Carr, Superficiales: ¿Qué está haciendo internet con nuestras mentes? Madrid, Taurus, 2017.

F. Fukuyama, The End of History and the Last Man. New York, Free Press, 1992.

D. Gelernter, "El estudio del Talmud", en John Brockman y Katinka Bateson, Eds., Así son las cosas, Debate, Madrid 1996, pp. 227-235.

J. L. González Quirós, El porvenir de la razón en la era digital, Madrid, Síntesis, 1998 (a).

J. L. González Quirós, "Progresar: la tecnología y la tradición antitecnológica", en C. Mellizo, Ed., Nacer, vivir, morir, Madrid, Noesis, 1998 (b), pp. 25-38.

J. L. González Quirós, Repensar la cultura, Madrid, EIUNSA, 2003.

J. L. González Quirós, y K. Gherab Martín, El templo del saber. Hacia la biblioteca digital universal, Barcelona, Deusto, 2006.

J.L. González Quirós y J. L. Puerta, "Tecnología, demanda social y medicina del deseo", Medicina Clínica, 133(16), 2009 (b), pp.671-675.

J. L. González Quirós, "El centauro Quirón”, en Revista Internacional de Tecnología, Conocimiento y Sociedad, ISSN 2174-8985, vol 2, nº1 2013 (a), pp. 99-108.

J. L. González Quirós, "Verdad y vida”, en J. Arana, Ed. Falsos saberes. La suplantación del conocimiento en la cultura contemporánea, Madrid, Bibioteca Nueva, 2013 (b), pp. 195-212,

A. Keen, The Cult of the Amateur, Nueva York, Doubleday, 2007.

M. Oakeshott, Moral y política en la Europa moderna, Madrid, Síntesis, 2008.

K. R. Popper, En busca de un mundo mejor, Barcelona, Paidos, 1994.

N. Postman, Technopoly: The Surrender of Culture to Technology, New York, Vintage, 2002.

H. Putnam, Razón, verdad e historia, Madrid, Teenos, 1988.

R. Rorty, Cuidar la libertad. Entrevistas sobre política y filosofía, Madrid, Trotta, 2005 . 


\section{José Luis González Quirós}

J. Surowiecki, The Wisdom of Crowds: Why the Many Are Smarter than the Few, and How Collective Wisdom Shapes Business, Economies, Societies, and Nations, Nueva York, Doubleday, 2004.

C. Truesdell, Ensayos de historia de la Mecánica, Madrid, Tecnos, 1975.

José Luis González Quirós jlgonzalezquiros@gmail.com 